\title{
Simonsen: Pioneiro da Visão Inercial de Inflação*
}

\author{
Valdir Ramalho**
}

Sumário: 1. Introdução; 2. História do pensamento; 3. Origem; 4. Desenvolvimento teórico; 5. Divulgação; 6. Comentários finais

Palavras-chave: indexação; inflação inercial; realimentação inflacionária.

Código JEL: B31; E64.

No final dos anos 60, Mário Henrique Simonsen chegou a uma visão de inflação que chamou 'Modelo de Realimentação Inflacionária'. Essa visão incluía, com outros nomes, certas noções que ficaram populares nos anos 80, tais como choque inflacionário, autoperpetuação de inflação e inflação institucionalizada pela indexação. Dentre os economistas brasileiros e eminentes, Simonsen foi o primeiro a defender a tese de que o dispositivo da correção monetária prejudica a eficácia do combate à inflação. Desde o início dos anos 70, ele pregou incansavelmente essa tese em aulas, livros, artigos e discursos ministeriais, repetindo que a correção monetária faz com que as altas de preços no passado determinem a inflação presente.

In the late 60s, Mário Henrique Simonsen arrived at a view of inflation which he called 'Model of Inflationary Feedback'. This view included, under different names, certain notions that became popular in the $80 \mathrm{~s}$, such as inflationary shock, self-perpetuating inflation, and inflation institutionalized through indexation. Among eminent Brazilian economists, Simonsen was the first to defend the thesis that indexation hampers the effectiveness of the fight against inflation. From the early 70 s on, he preached this thesis in his classes, his books, articles and speeches as a finance minister, stressing that, due to indexation, price rises in the past determined inflation in the present.

\footnotetext{
${ }^{*}$ Artigo recebido em jul 2001 e aprovado em dez. 2001. Este artigo foi escrito juntamente com outro que focaliza as raízes internacionais de noções fundamentais do inercialismo Ramalho (2000). O autor agradece a todos que, em diversas ocasiões, exprimiram suas opiniões sobre ambos os textos (cujas primeiras versões circularam em 1997). Em particular, comentários de um parecerista motivaram algumas modificações neste texto, bem como indicaram a literatura recente sobre Simonsen.

${ }^{* *}$ Professor universitário e consultor de pesquisas em ciências sociais e humanidades.
} 


\section{Introdução}

Durante sua vida extremamente produtiva dedicada à análise econômica, Mario Henrique Simonsen legou-nos muitos artigos e livros de elevada qualidade técnica. Simonsen sabia escrever com simplicidade, clareza e concisão, ao mesmo tempo que seus textos bem organizados transmitiam raciocínios e modelos econômicos de conteúdo rico e atualizado. Ao longo de várias gerações de economistas no Brasil, anteriores e contemporâneas à de Simonsen, é difícil encontrar alguém que estivesse tão entrosado na mais avançada literatura internacional de economia de seu tempo. E, através do exemplo da sua obra, Simonsen divulgou entre nós a importância do emprego da matemática na economia. Ademais, Simonsen empenhou-se em promover excelência na formação de economistas no país, por meio de cursos de reciclagem e da pós-graduação em economia, da qual foi um dos pioneiros no Brasil.

Recentemente, discussões sobre qual sejam a extensão e os limites da contribuição de Simonsen ao conhecimento econômico no Brasil apareceram em Barbosa (1997), Boianovsky (1999), Campos (1998), Cysne (2001), Werlang (1998) e outros artigos em um número especial da Revista Brasileira de Economia. A visão da inflação como fenômeno inercial é incluída como ítem importante dessa contribuição. Uma tarefa distinta, também útil ao estudo da evolução do pensamento econômico no país, é a de levantar, narrar e documentar as origens do interesse de Simonsen pelas noções básicas daquela visão, bem como o subsequente desenvolvimento delas em seus escritos.

Este artigo dá um passo inicial nessa direção, fornecendo um curto panorama do surgimento e desenvolvimento, nos escritos de Simonsen, das noções de realimentação da inflação e de reprodução da inflação passada na inflação presente. Com o objetivo de destacar o pioneirismo de Simonsen, este artigo focaliza apenas suas idéias anteriores aos anos 80, quando ele (solitariamente, pelo menos até o meio dos anos 70) colocou em primeiro plano de sua obra e de seus pronunciamentos os conceitos básicos da visão inercial. Está fora do escopo deste artigo a década de 80, quando a explicação inercialista espalhou-se rapidamente entre os economistas brasileiros e até mesmo passou a ser tema corriqueiro de artigos de jornais e de colunas econômicas dos mais diversos autores. Os períodos antes e depois de 1980 correspondem a um contraste aproximado entre, por um lado, o surgimento das noções básicas e, por outro, elaborações mais refinadas, formalizações e detalhamentos técnicos. Por maiores que sejam os avanços técnicos atribuíveis a Simonsen ou a outros nos anos 80 e 90, eles devem ser distinguidos das noções básicas praticamente comuns a todas as escolas no Brasil que, a partir dos anos 
80, adotaram alguma variante da visão inercial.

Para Simonsen, no contexto dos anos 70, correção monetária é o reajustamento periódico do valor nominal de preços contratados, sendo tais reajustes com base em números-índices observados de um índice de preços estabelecido em contrato. Os reajustes são automáticos por força de contrato. A análise de Simonsen tem um caráter geral - independe de que os contratos indexados sejam contratos de salários ou outros tipos de contrato. Seu foco em aspectos gerais deve ser distinguido de considerações sobre questões específicas de algum tipo de contrato, tais como a questão de picos e médias nos contratos salariais. Nos anos 60 e 70 no Brasil (com a exceção, pouco ouvida, de Francisco Lopes no final do período), não se pensava em reajustes salariais e em dinâmica salarial quando se falava de prós ou contras da correção monetária. As listas típicas dos ítens sujeitos a indexação caracteristicamente não incluíam salários (por exemplo, Simonsen (1970, p. 184-188). Segundo Simonsen, a possibilidade de indexar salários tinha sido "contornada" ou "evitada" pela adoção da política salarial do governo do general Castello Branco (1971, p. 26).

Essa política salarial era vista como um dispositivo peculiar, porque ela estabelecia reajustes com base em cifra oficial de 'inflação esperada'; e isto não era considerado correção monetária pela grande maioria dos economistas na época. Outra razão é que, na análise de então, a política salarial da época era tida como favorecendo a queda da inflação, de modo que se buscaram em outros fatores explicações para a persistência da inflação em $20 \%$ ao ano no início dos anos 70 (e, depois, para sua aceleração desde 1974). A justificativa de adoção dessa política salarial tinha sido evitar inflação de custos, pois as elevações de salários tinham sido diagnosticadas como acréscimos de custos, não como fator de propagação ou realimentação da inflação. Este tipo de diagnóstico não foi modificado nos primeiros anos de surgimento da análise da indexação por Simonsen. A mentalidade de focalizar dinâmica salarial, contratos salariais, como eixo fundamental de modelos macroeconômicos de inflação caracteriza os anos 80, em contraste com os anos 70 .

O resto deste artigo está organizado assim: coloco algumas considerações de procedimentos na seção seguinte e divido a narrativa da evolução da visão inercialista de Simonsen em três etapas. A origem é abordada na terceira seção, o desenvolvimento teórico na quarta seção, e a fase de divulgação na quinta. A última seção é um breve comentário final. 


\section{História do Pensamento}

Paulatinamente vem aumentando a receptividade a relatos históricos nas novas gerações do nosso meio acadêmico. São poucos os que não vêem contribuição acadêmica no penoso esforço de montar uma estória, garimpar documentos, selecioná-los e identificar as partes mais importantes a serem exibidas. Sendo assim, vale a pena rever brevemente certas características desse tipo de esforço. O procedimento fundamental do relato histórico é contar uma estória, ou seja, expor o encadeamento de alguns eventos que, por alguma razão, são bastante importantes para serem recordados. Nos campos da história da ciência e da história do pensamento, citações constituem exibições de documentos históricos. Por isso, diferentemente do que acontece em trabalhos com outras finalidades, este artigo contém citações em abundância. Nisto segue a técnica usual de trabalhos de exposição, análise ou apreciação crítica do pensamento de figuras de relevo. Eles costumam ter um número alto de citações por página, por três razões.

Primeiro, a função do trabalho é exatamente demonstrar o que pensa o autor estudado. As reproduções de passagens são exibidas como evidências de uma interpretação desse pensamento.

Segundo, somente parafrasear o autor em foco poderia deixar no leitor a dúvida legítima de que a paráfrase provavelmente usa uma linguagem mais recente, e, por isso, distorce o pensamento daquela pessoa; por exemplo, inventa ou exagera seu pioneirismo. Assim, a declaração de que a inflação presente repete a inflação passada era tão comum e tão típica nos anos 80, que o leitor poderia duvidar de que Simonsen teria feita declaração de idêntico teor muitos anos antes, se este artigo não reproduzisse seu próprio texto. E mesmo deparando-se com uma dessas declarações, o leitor poderia achar que houve uma coincidência de estrutura de frases, mas que a idéia não teria tido importância no pensamento de Simonsen. A repetição de citações de teor semelhante tem como objetivo mostrar que certas sentenças não passaram apenas momentânea e fugazmente pela cabeça do autor estudado; elas não eram uma raridade ou acidente sem importância, mas uma preocupação freqüente do citado.

Terceiro, trabalhos do tipo mencionado muitas vezes focalizam escritos de muitos anos atrás, hoje escondidos e espalhados em meio a volumosa literatura que se acumulou em bibliotecas por décadas a fio. Se um artigo que resenha tais escritos não aproveitasse para reproduzir os trechos pertinentes, cada leitor que quisesse conferi-los, ou usá-los de outro modo, teria que gastar muito tempo para localizá-los. 
História do pensamento não se confunde com retrospectos de literatura (surveys). Nestes, o escritor faz muitas referências, mas não precisa citar muito; organiza as idéias em torno de tópicos fundamentais; compara os autores em foco sob a ótica de diversas categorias ou hipóteses; e a finalidade é apresentar uma avaliação das idéias abordadas. No primeiro caso, citações formam evidência essencial; organizam-se idéias em função de encadeamento no tempo; comparam-se autores em foco em função de épocas e de quem influenciou quem; e a finalidade é estruturar uma exposição de fatos que são importantes para conhecer. Não há necessidade que o escritor de um trabalho histórico se posicione contra ou a favor dos fatos (no caso de história do pensamento, concorde ou discorde das idéias expostas).

Já se disse que um relato histórico não tem originalidade, pois seu autor "apenas descreve fatos". Ou seja, originalidade seria inventar o seu objeto de estudo. Por esse critério, cabe perguntar como fica a originalidade do econometrista que não inventa os dados e as fórmulas que usa, e a do modelador que não inventa as técnicas matemáticas que emprega. Ademais, há muitas descrições possíveis para a mesma série de episódios, assim como os mesmos dados se encaixam em muitas regressões possíveis.

O passado está cheio de pessoas interessantes e idéias frutíferas, sugere Mary Morgan no seu The History of Econometric Ideas (1990, p. XI). Samuel Hollander, no seu Classical Economics, explica que, na história do pensamento econômico, nós revivemos processos mentais de economistas excepcionalmente inteligentes e envolvidos com problemas fora do comum (1987, p. 3). Jürg Niehans, que se tornou conhecido pelos seus livros de economia monetária, lançou o seu A History of Economic Theory acreditando que a dinâmica da pesquisa encontra direções ao relembrar o passado e, desta maneira, pode aumentar sua produtividade (1990, p. IX).

Narrar uma estória é tão importante para a construção do conhecimento como montar um modelo matemático ou estimar algumas regressões. É simplesmente imaturo o paroquialismo daqueles que somente valorizam o que eles mesmo sabem fazer, e para quem seus próprios procedimentos são os "consagrados". Carecem de história, porque uma das funções desta é exatamente alargar as perspectivas da mente (McCloskey, 1976, p. 452-454). Mas não há espaço aqui para alongar-se sobre a relevância da investigações históricas. Recomenda-se o clássico Does the Past have Useful Economics?, de McCloskey (1976). 


\section{Origem}

Mario Henrique Simonsen é provavelmente o mais antigo defensor no Brasil da controversa tese de que o dispositivo da correção monetária é prejudicial ao objetivo antiinflacionário. Por vários anos, sozinho entre economistas com escritos de qualidade acadêmica, ele pregou incansavelmente a mencionada tese em aulas, livros, artigos e discursos ministeriais. Assim, ele pode ser considerado o originador no Brasil do movimento contrário ao dispositivo e que acabou por eclodir nos anos 80 .

$\mathrm{Na}$ fase inicial (anos 60 e início dos anos 70) do período que nos interessa aqui, Simonsen freqüentemente aderiu a uma visão de inflação típica do keynesianismo convencional (o que muitos chamavam de 'monetarismo' na época, mas que não é a visão de Milton Friedman); declarou várias vezes que a inflação no Brasil resultava não só da política monetária expansionista, mas também de outras causas independentes, como o impacto de déficits públicos sobre a demanda agregada e a elevação de custos advinda de aumentos salariais (por exemplo, Simonsen, 1964, p. 20-21). Paralelamente, em diversas passagens de seus escritos, ele descreveu a inflação como determinada por um conflito distributivo em torno de fatias do produto (por exemplo, Simonsen 1969, p. 124-125). Uma formulação extremamente bem feita da corrente do conflito distributivo é a seguinte:

"O processo inflacionário, afinal, resulta apenas da tentativa de se implantar um conjunto de aspirações incompatíveis da sociedade, do desejo de dividir o bolo em fatias de soma superior ao todo." (Simonsen, 1969, p. 150).

Esta maneira de ver a inflação foi mantida no período em que Simonsen foi ministro da fazenda no governo do general Ernesto Geisel, como o mostra discurso de abril de 1974:

"A existência de uma inflação crônica é sinal de que a sociedade está tentando dividir o produto nacional em partes cuja soma é superior ao todo." (Simonsen, 1976a, p. 17-18).

Neste contexto, uma questão interessante é quando precisamente Simonsen começou a encontrar defeitos de caráter macroeconômico no dispositivo de correção monetária. Nos seus mais antigos escritos sobre inflação não há qualquer referência ou comentário sobre indexação. Este é o caso de seus artigos A Inflação no Brasil, de 1963, escrito para a CONSULTEC, e A Política Antiinflacionária do Governo, de 1965. Contudo, vale a pena notar no artigo de 1963 uma das primeiras menções de Simonsen à visão do conflito distributivo, quando ele descreve os países latinoamericanos como tendo aspirações cada vez mais altas de expansão econômica:

"Em tais condições é natural que as reivindicações dos diferentes grupos sociais 
quanto à participação na renda real do país formem um sistema incompatível em face das limitações da capacidade produtiva. Nessas circunstâncias é grande a tentação dos governos em aceitar sistemas incompatíveis de reivindicações pelo desencadeamento de um processo inflacionário" (p. 214).

Também não aparecem referências a aspectos problemáticos da indexação no livro A Experiência Inflacionária no Brasil (Simonsen, 1964), onde há uma seção sobre o programa antiinflacionário da administração do general Humberto Castello Branco. As menções muito breves à indexação informam as medidas de correção monetária recém-promulgadas pelo governo (p. 46, 51, 52, 61, 93). Posteriormente, os editoriais escritos por Simonsen para a Carta Apec, republicados no livro Ensaios sobre Economia e Política Econômica (Simonsen, 1971a), não contêm, até 1968, quaisquer sinais de sua famosa crítica. Em particular, esse é o caso de dois editoriais. Um, de maio de 1968, e intitulado "Correção Monetária dos Aluguéis" (Simonsen, 1971a, p. 64-65), trata de um projeto de governo que visava tornar parcial a correção monetária dos aluguéis. Na opinião de Simonsen, isso seria conter artificalmente altas de preços, combater a inflação apenas pelos sintomas, quebrando um sadio princípio de realismo econômico. O outro, de julho de 1968, que trata do tema de forma abrangente, e intitula-se "Correção Monetária" (Simonsen, 1971a, p. 83-84), considera "inadmissível... qualquer arranhão no princípio da correção monetária". A apostila "Aspectos da Inflação Brasileira" (1972c), cujo texto provavelmente foi escrito em 1966, tampouco critica a correção monetária.

A julgar pela época em que surgem as primeiras críticas de Simonsen à correção monetária, este ponto de vista desenvolveu-se em sua mente no período entre julho de 1968 e março de 1969, ou, no máximo, setembro de 1969. Esta também é a época em que Simonsen modificou sua apreciação do controle de preços (como se verá abaixo), e provavelmente os processos de modificação de opinião sobre um e outro tópico estão relacionados.

O que é possivelmente a primeira alusão ao alegado defeito macroeconômico da indexação aparece no livro Brasil 2001 (Simonsen, 1969), cujo prefácio é datado de março de 1969. A alusão é feita quando, no início de uma sentença sobre benefícios do dispositivo, seu autor faz uma ressalva:

"Embora a correção de alguma forma realimente a taxa inflacionária,..." (p. 141).

Segue-se uma inédita menção a problemas de convivência com a inflação que não se resolvem com a correção monetária, e, pela primeira vez, uma especulação sobre indexação generalizada, colocando-a sob ângulo desfavorável.

Simonsen tinha o hábito de reproduzir ou rescrever parágrafos de seus textos 
em trabalhos posteriores. Ademais, tinha um estilo característico. Isso permite identificar como de sua autoria uma pequena seção no livro Correção Monetária, de Julian Chacel, Mario Henrique Simonsen e Arnoldo Wald (1970, p. 285); nessa seção há uma segunda referência à correção monetária como "realimentador da taxa de inflação" (p. 285). A fase final de redação do livro terminou em setembro de 1969. Uma terceira referência foi feita no editorial para a Carta Apec com título "Inflação e Desenvolvimento", de fevereiro de 1970 (Simonsen, 1971a, p. 72). Outra menção, mais importante, é feita no editorial para a Carta Apec com título "Inflação: Política e Resultados", de julho de 1970 (Simonsen, 1971a, p. 7577). Nesta lê-se uma das primeiras formulações feitas por Simonsen do conhecido slogan inercialista que joga com a imagem de passagem de altas de preços do passado para o presente (ou do presente para o futuro):

"... o atual processo inflacionário brasileiro parece conter uma forte componente de realimentação - a inflação persiste no presente porque existiu no passado." (p. 77)

Ademais, este editorial usa os termos 'resistência' e 'dificuldade' para atribuir à indexação uma maior resistência da inflação à queda e uma maior dificuldade de se combater a alta de preços.

Julho de 1970 é também a data do prefácio ao livro Inflação: Gradualismo $x$ Tratamento de Choque (Simonsen, 1970), onde seu autor volta ao tema:

"... a correção monetária atua como um realimentador automático de inflação." (p. 16; há sentença semelhante na p. 191)

Uma extensa parcela do livro trata de realimentação inflacionária (capítulos 6 e 8) e se localiza próxima ao meio do texto. Ela pode ter sido escrita em 1969, provavelmente na segunda metade do ano (supondo-se, com certa plausibilidade, que os capítulos seguintes tenham sido escritos no primeiro semestre de 1970).

A diferença de posições de Simonsen sobre controle de preços está registrada em dois editoriais da Carta Apec com o mesmo título: "Controle de preços". No primeiro, de janeiro de 1968 (Simonsen, 1971a, p. 55-56), ele acusa vigorosamente o ministro Antônio Delfim Neto, que ocupava o ministério da fazenda no início do governo do general Arthur da Costa e Silva, de esconder os sintomas da inflação. Esta era uma posição antiga de Simonsen, pois já no livro A Experiência Inflacionária no Brasil (Simonsen, 1964) há uma breve referência desfavorável a uma experiência desses controles (p. 70). Mas, no segundo editorial, de maio de 1970 (Simonsen, 1971a, p. 73-74), Simonsen conclui que os controles de preços dos últimos anos de então tinham sido saudáveis, com base no seguinte:

"Há, contudo, um argumento ponderável a favor dos controles de preços num programa de estabilização monetária. Eles podem constituir a forma mais simples 
de se frear a taxa de inflação com o mínimo de crise de estabilização." (Simonsen, 1971, p. 73-74)

Cabe notar que a preocupação com encontrar uma forma de enfraquecer a ligação entre redução ou eliminação da inflação e queda da atividade econômica ou do crescimento econômico é um elemento comum entre essa passagem e a visão inercial da inflação. O texto desse segundo editorial foi incorporado ao livro Inflação: Gradualismo x Tratamento de Choque (nas págs. 139-142) com várias revisões de passagens, enfatizando os malefícios da indexação. No trecho citado acima, por exemplo, "frear a taxa de inflação com o mínimo de crise de estabilização" foi substituída por "reduzir o coeficiente de realimentação".

\section{Desenvolvimento Teórico}

No livro Inflação: Gradualismo x Tratamento de Choque, Simonsen lançou o que mais tarde foi chamado de Modelo da Realimentação Inflacionária ou, mais brevemente, Modelo da Realimentação (a partir de Simonsen, 1972a, p. 165; ver também, 1973, p. 119). O modelo é representado por uma equação onde a taxa de inflação é colocada como função linear de três variáveis interpretadas como componentes da inflação (1970, p. 127-139). A base do modelo, uma equação de diferenças finitas de preços em função de preços defasados, era muito comum desde o pós-guerra, conforme Harry Johnson (1963, p. 118-119). O próprio Johnson reproduziu uma equação dessas:

$$
P(t)=a b \cdot P(t-1)+c
$$

onde $P(x)$ designa o nível de preços, ou, alternativamente, a variação do o nível de preços, no período $x(x=t$ ou $x=t-1)$; $c$ designa uma "perturbação exógena", e $a$ e $b$ são constantes.

Simonsen interpretou essa equação em termos de taxas de inflação e, sobretudo, estendeu-a, introduzindo um componente que representa o impacto da demanda agregada. Somente anos mais tarde se percebeu que, com isso, a equação passou a se assemelhar a uma Curva de Phillips, empregando diferenças finitas. Isso não chega a surpreender, pois, de fato, o problema que Simonsen tentou originalmente resolver, ao construir o modelo, foi explicar a ocorrência de queda do produto quando se combate a inflação (Simonsen, 1970, p. 126-127); e a resolução desse problema também é um dos principais propósitos da literatura em torno da Curva de Phillips. Mas, além disso, Simonsen introduziu outro componente para representar o que chamou de 'inflação autônoma', e, sobretudo, interpretou a inflação 
do período passado como sendo o impacto da correção monetária. A equação de Simonsen é

$$
r(t)=a(t)+b \cdot r(t-1)+c \cdot[g(t)-n]
$$

onde $r(x)$ designa a taxa de inflação no período $x(x=t$ ou $x=t-1) ; a(t)$ designa a 'inflação autônoma', $g(t)$ designa a taxa de crescimento da demanda, e $n$ designa a taxa não-inflacionária de crescimento da demanda. A variável $g(t)$, chamada de "componente de regulagem da demanda", guarda correspondência com a que aparece na curva de Phillips representando o impacto do nível de emprego agregado sobre a inflação.

Deste modo, a equação sintetizou pontos cruciais em termos concisos e simples, expostos por Simonsen nos seguintes termos (como muitos de sua geração, ele tem o hábito de usar a palavra 'componente' no feminino):

"A componente de realimentação é definida como aquela que resulta da inflação do período anterior. (...) Tal componente corresponde... de um modo geral, a todas as revisões de preços tornadas automáticas pela legislação sobre correção monetária." (1970, p. 128).

"O parâmetro b, que será denominado coeficiente de realimentação, indica o grau de automatismo da inflação crônica, isto é, em que fração a inflação de um período se transmite ao período seguinte." (1970, p. 129; ver também p. 137).

Como se pode ver, as passagens acima refletem claramente a tese central do inercialismo de que, em uma inflação crônica, devido aos reajustes automáticos de preços resultantes da indexação, a inflação do período presente reflete, em grande parte, a inflação do período passado.

A terceira variável na equação de Simonsen designa a "componente autônoma", ou seja, as variações da taxa de inflação que decorrem de fatores aleatórios (1970, p. 132) e eventos como más safras, aumentos de impostos indiretos, reajustes excepcionais da taxa de câmbio, de salários, ou de tarifas públicas $(1970$, p. 127128,133). É óbvio que Simonsen tinha em vista o que a literatura de inflação de custos, margens e conflito distributivo eventualmente chamou de choques inflacionários, expressão que mais tarde os inercialistas passaram a usar com mais freqüência do que se fazia antes. O termo "autônomo" era tradicionalmente usado na literatura macroeconômica até os anos 60 , por influência da visão keynesiana. Comumente representava-se algum fator econômico como formado de dois componentes, um "induzido" e outro "autônomo"; o primeiro componente variava em função da renda ou de outra força econômica explicada no contexto de algum modelo teórico, enquanto que o segundo era determinado por forças exógenas ao modelo. 
Por conseguinte, na linguagem que se tornou usual dos anos 80, a equação acima nos diz que a inflação presente é determinada pela inflação passada, na proporção do grau de indexação; e também por choques inflacionários de oferta e por choques de demanda.

Com base em seu Modelo de Realimentação, Simonsen enunciou pelo menos três teses típicas do inercialismo:

- os resultados de um combate à inflação serão tão mais rápidos quanto mais se baixe o coeficiente de realimentação (1970, p. 130-138).

- pode-se reduzir a inflação até o nível da inflação autônoma, sem recessão, desde que se elimine a realimentação (1970, p. 130-131, 135-136, 138, 180). Em outras palavras, na ausência de choques inflacionários (que geram a inflação autônoma), é possível extinguir a inflação através de desindexação total, sem recessão (ver também 1972a, p. 165).

- O controle de preços é uma forma eficaz de reduzir o coeficiente de realimentação (1970, p. 140-142,215).

Há uma quarta tese inercialista implícita na combinação de certas sentenças sobre inflação crônica e sobre coeficiente de realimentação alto (1970, p. 129, 134, 140), mas que só foi enunciada em escritos posteriores:

- Em uma inflação crônica, o coeficiente de realimentação se aproxima da unidade, e a taxa de inflação se estabiliza (Simonsen, 1974:102). Em outras palavras, uma inflação crônica é aproximadamente inercial.

Uma diferença entre o que Simonsen pensava na época e o que os inercialistas dos anos 80 propuseram é que ele nunca levou a sério a possibilidade de um fim súbito da inflação, concentrando-se em analisar trajetórias alternativas de gradualismo. Em conseqüência, surge uma outra diferença: Simonsen considerou controles de preços, mas não sua forma mais extremada, o congelamento de preços. Uma terceira diferença é que pronunciamentos mais radicais de inercialistas ignoraram a demanda agregada.

\section{Divulgação}

Em 1971, a revista Visão escolheu Simonsen para conceder o título de Homem de Visão. No discurso de agradecimento, publicado em dezembro, Simonsen 
(1971b) retornou ao tema da indexação, enunciando mais uma vez o típico slogan inercialista. Ele disse que um defeito da correção monetária é

“... o de criar certo grau de realimentação inflacionária — os preços passam a subir hoje porque houve inflação um ano atrás." (p. 20)

O Modelo da Realimentação e passagens semelhantes às citadas acima encontram-se também no livro Brasil 2002 (Simonsen, 1972, p. 78, 83, 91-94, 165-171); no artigo "O modelo da realimentação inflacionária e as experiências de estabilização" (Simonsen, 1972c); no capítulo IX de sua segunda apostila intitulada Teoria do Equilibrio Agregativo a Curto Prazo (Simonsen:1973a); no correspondente capítulo XIII do segundo volume de seu primeiro livro de macroeconomia (Simonsen:1973b), onde foram reeditadas as duas citadas apostilas; e no capítulo V, intitulado "A Política Antiinflacionária" (Simonsen, 1974, p. 79-118) do livro A Nova Economia Brasileira, de Simonsen e Roberto Campos. Nesses trabalhos vale sobretudo notar as muitas variações de sentenças que contrastam presente e passado (por exemplo, em Simonsen, 1972, p. 91, 165, 166, 167, 168; 1972a, p. 231,$239 ; 1974$, p. 96, 97).

Em uma dessas sentenças no livro Brasil 2002 aparece uma das primeiras versões do slogan inercialista (Simonsen, 1972a, p. 91), que é repetida letra por letra no artigo sobre o modelo da realimentação (Simonsen, 1972b, p. 239), na segunda apostila de macroeconomia (Simonsen, 1973a, p. 161) e finalmente no livro de macroeconomia (1973b:130-131):

"A correção monetária e a taxa flexível de câmbio fazem que os preços subam hoje porque subiram ontem, ou este ano porque subiram no ano passado."

A expressão 'taxa flexível de câmbio' diz respeito ao regime de minidesvalorizações cambiais da época, ou seja, taxas de câmbio estabelecidas oficialmente e atreladas a índices de preços. É relevante que se aprecie mais uma versão do slogan inercialista, onde se fala pela primeira vez da desindexação; esta é posta em contraste com as políticas de choques de demanda ou de custos, as quais teriam efeitos recessivos.

"Tais observações sugerem que uma inflação crônica deve conter apreciável componente de realimentação. Os reajustes presentes de preços não resultam, em boa parte, de pressões autônomas da demanda ou dos custos, mas simplesmente da inflação passada. Esse efeito de realimentação cria apreciável rigidez nos processos inflacionários crônicos. Estancar uma alta continuada de preços exigiria ou a interrupção desse automatismo ou sua neutralização por pressões deflacionárias autônomas, as quais exerceriam certos efeitos depressivos sobre a produção e o emprego." (Simonsen, 1972a, p. 165; também em 1972b, p. 231, onde 'deflacionárias' é trocado erroneamente por 'inflacionárias'). 
Na citação acima, a desindexação é referida pela expressão "interrupção de automatismo".

De março de 1974 a fevereiro de 1979, Simonsen foi ministro da fazenda no governo do general Ernesto Geisel. Quando iniciou suas atividades como ministro, os economistas do país alimentavam uma imagem favorável e simpática da indexação, graças ao papel que ela teria desempenhado nas políticas econômicas das três administrações militares passadas. Simonsen logo dedicou-se com afinco à tarefa de modificar esta opinião, lançando mão do fato de que suas declarações eram naturalmente foco de interesse dos meios de comunicação. Já em outubro de 1974, o ministro teceu algumas considerações sobre "os efeitos de realimentação da correção monetária" (1976a, p. 77) e enunciou mais uma variante do slogan do inercialismo:

"A correção monetária significa que os preços aumentarão hoje porque se elevaram ontem, e que se elevarão neste ano porque aumentaram no ano passado." (p. 76).

Ao lado de muitas referências à realimentação inflacionária, os diversos discursos do ministro Simonsen continuaram repetindo o slogan inercialista no período 1974-1978 (ver Simonsen, 1976b, p. 27; 1977a, p. 10, 35; 1977b, p. 23, 47-48; 1978 , p. 35, 57, 85-86, 101, 134).

Vale a pena citar mais umas poucas variações do slogan. Elas apresentam formulações levemente diferentes, que fazem menção a perpetuação e a estabilização da inflação:

"Este quadro ... é o da inflação gerando a própria inflação, e tendendo a perpetuar-se em patamares." (Simonsen, 1978, p. 85-86).

"É preciso compreender que, se todos reajustam salários, preços e lucros na proporção da inflação passada, o melhor que se pode conseguir não é estabilizar a moeda, mas apenas estabilizar a taxa de inflação." (Simonsen, 1978, p. 101).

\section{Comentários Finais}

Naturalmente, Simonsen não ficou só por muito tempo em sua campanha intelectual contra a indexação. Entre os autores que não foram examinados aqui está, por exemplo, Francisco Lopes, um talentoso economista que acompanhou Simonsen nos anos 70 e que o assessorou durante parte de sua atuação no ministério da fazenda do governo do general Geisel. Em 1975, tanto Lopes como Simonsen se interessaram em construir uma teoria normativa do controle de preços. A partir do meio dos anos 70, Lopes engajou-se em um programa de pesquisa que consistiu sobretudo em elaborar em detalhe o modelo do conflito distributivo, incorporando 
a tese do salário médio real como meta adequada de política econômica, bem como a existência de contratos indexados. Lopes refinou e solidificou a crítica de Simonsen à correção monetária, colocando-a como proposição fundamental de modelos mais detalhados de determinação da inflação (Lopes, 1976) e (Lopes e Williamson, 1980), que já circulava desde 1978).

Este artigo visa mostrar que Mario Henrique Simonsen foi pioneiro na exposição e divulgação no Brasil da tese de que o dispositivo da correção monetária torna a inflação inercial e é prejudicial ao objetivo antiinflacionário. Como parte dessa tarefa, chamou-se a atenção para os mais antigos escritos de Simonsen sobre inflação, hoje pouco conhecidos e ainda pouco explorados na reconstituição da trajetória intelectual deste. A relação de precedência intelectual entre Simonsen e a escola inercialista não é vista claramente por muitos economistas brasileiros, não só devido ao ainda insuficiente cultivo entre nós da pesquisa na história do pensamento econômico, mas também por causa de certo desacordo entre Simonsen e os inercialistas no meio dos anos 80. A distância entre Simonsen e eles (mencionados em certas críticas de Simonsen como 'heterodoxos' ou como responsáveis pelo Plano Cruzado) foi criada pela prevalência do inercialismo extremado às vésperas e durante o Plano Cruzado. Os escritos de Simonsen deixam claro que, na maior parte do tempo, ele pensava que o processo inflacionário era sensível a políticas de demanda, especialmente por que ele passou a ver o coeficiente de realimentação como influenciável por essas políticas.

\section{Referências}

Barbosa, F. H. (1997). Contribuição Acadêmica de Mário Henrique Simonsen. Revista de Econometria, 17(1):115-130.

Boianovsky, M. (1999). Simonsen and the early history of the cash-in-advance approach. Anais do 2\% Encontro Nacional de Economia, 1:603-613. Belém: ANPEC.

Campos, R. (1998). Mário Henrique Simonsen, um matemático humanista. Revista Brasileira de Economia, 52(especial):9-14.

Chacel, J., Simonsen, M. H., \& Wald, A. (1970). A Correção Monetária. Apec, Rio de Janeiro.

Cysne, R. (2001). Mario Henrique Simonsen. Estudos Avançados, 15(41):139-154.

Hollander, S. (1987). Classical Economics. Basil Blackwell, Oxford. 
Johnson, H. (1963). A survey of theories of inflation. In Allen, G. \& Unwin, ., editors, Essays in Monetary Economics, chapter 3, pages 104-142. London, 2nd edition.

Lopes, F. (1976). Inflação, correção monetária e controles de preços. Revista Brasileira de Economia, 30(4):427-455.

Lopes, F. \& Williamson, J. (1980). A teoria da indexação consistente. Estudos Econômicos, 10(3):61-99.

McCloskey, D. (1976). Does the past have useful economics? Journal of Economic Literature, 14(2):434-461.

Morgan, M. (1990). The History of Econometric Ideas. Cambridge University Press, Cambridge.

Niehans, J. (1990). A History of Economic Theory. Johns Hopkins University Press, Baltimore.

Ramalho, V. (2000). As raízes conceituais do inercialismo. Análise Econômica, 18(33):101-119.

Simonsen, M. H. (1963). A Economia Brasileira e Suas Perspectivas. APEC Editora, Rio de Janeiro. Estudos Semestrais APEC - n. 2.

Simonsen, M. H. (1964). A Experiência Inflacionária No Brasil. Ipês, Rio de Janeiro.

Simonsen, M. H. (1965). A Política Antiinflacionária Do Governo. APEC Editora, Rio de Janeiro. A Economia Brasileira e suas Perspectivas - Estudos APEC n. 4 .

Simonsen, M. H. (1969). Brasil 2001. Apec, Rio de Janeiro.

Simonsen, M. H. (1970). Inflação: Gradualismo x Tratamento de Choque. Apec, Rio de Janeiro.

Simonsen, M. H. (1971a). Aspirar à normalidade democrática. Visão, 39(11):1921.

Simonsen, M. H. (1971b). Ensaios Sobre Economia e Política Econômica. Apec, Rio de Janeiro. 
Simonsen, M. H. (1971c). A estrutura econômica brasileira. Ensaios Econômicos da EPGE, (3). Fundação Getulio Vargas / EPGE.

Simonsen, M. H. (1972a). Aspectos Da Inflação Brasileira. Fundação Getulio Vargas / EPGE, Rio de Janeiro.

Simonsen, M. H. (1972b). Brasil 2002. Apec/Bloch, Rio de Janeiro.

Simonsen, M. H. (1972c). O modelo da realimentação inflacionária e as experiências de estabilização. Revista Brasileira de Economia, 26(4):227-239.

Simonsen, M. H. (1973a). Macroeconomia, volume vol. 2. APEC, Rio de Janeiro.

Simonsen, M. H. (1973b). Teoria Do Equilíbrio Agregativo a Curto Prazo, volume vol. II - Teoria Keynesiana. Fundação Getulio Vargas / EPGE, Rio de Janeiro.

Simonsen, M. H. (1974). A política antiinflacionária. In Simonsen, M. H. e Campos, R., editor, A Nova Economia Brasileira, chapter 5, pages 79-118. Livraria José Olympio, Rio de Janeiro.

Simonsen, M. H. (1976a). Palestras e conferências: 1974. Vol. 1, Rio de Janeiro: Ministério da Fazenda.

Simonsen, M. H. (1976b). Palestras e conferências: $1^{o}$ semestre de 1975. Rio de Janeiro: Ministério da Fazenda.

Simonsen, M. H. (1977a). Palestras e conferências: 1977. Rio de Janeiro: Ministério da Fazenda.

Simonsen, M. H. (1977b). Palestras e conferências: $1^{o}$ semestre de 1976. Rio de Janeiro: Ministério da Fazenda.

Simonsen, M. H. (1978). Palestras e conferências: 1978, vol. Rio de Janeiro: Ministério da Fazenda.

Werlang, S. (1998). Simonsen, inflação, expectativas racionais e os póskeynesianos. Revista Brasileira de Economia, 52(n. especial):161-166. 